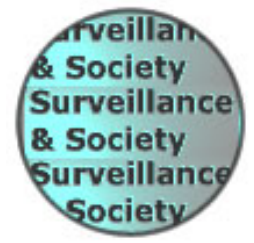

\title{
Editorial: Smart Borders and Mobilities: Spaces, Zones, Enclosures
}

\section{Louise Amoore1, Stephen Marmura2 and Mark B. Salter3}

The border has been called the fundamental political institution; and the bordering process is one of the most important roles for community, delineating between inside and outside, us and them, safe and dangerous, known and unknown. Borders represent both an appeal to the limits in politics and of political community, and a technology of limits - a means of defining what is possible in the governing of life itself. Yet, even as border management has taken on a renewed emphasis for policy makers, assessing the border's status as a definable, concrete entity or process has become increasingly problematic. As we write this editorial, for example, the British government announces the extension of biometric controls, security gates, scanning and screening into the public spaces of the railway station, shopping mall and sports stadium. In addition to its traditional geophysical characteristics, the border has taken on virtual, de-territorialized attributes as well. Castles, walled cities, and extensive border battlements have been replaced by gated communities, expansive border zones, and management by "remote control." The contemporary border is constituted as much by data-flows, artificial zones and spaces of enclosure that seep into the city and the neighbourhood, as by older state and geographic boundaries.

This issue of Surveillance \& Society considers the evolving character of the international border in the wake of new security and trade agreements, burgeoning state and commercial surveillance practices, and the increasing global mobility of persons, objects and information. Featured here are four full-length articles and a multi-media artistic presentation which draw attention to reconfigurations of the border catalyzed by the new security and surveillance regimes which have coalesced in the years following 9/11. The contributors explore a variety of theoretical and substantive issues including the historic origins of surveillance practices now associated with border regulation, the border's increasing dispersal into differentiated spatial and temporal zones, the emergence of new surveillance paradigms, the simulacral and performative aspects of border security, and the differential effects of border management and risk assessment for various categories of persons.

\footnotetext{
1 Department of Geography, Durham University, UK. mailto:louise.amoore@durham.ac.uk

2 The Surveillance Project, Queens University, Kingston, Ontario. mailto:9smem@post.queensu.ca

3 School of Political Studies, University of Ottawa. mailto:msalter@uOttawa.ca
} 
As Zureik and Salter (2005: 4) observe, the presumed isomorphism among sovereignty, nationality and territory has been undone by the transportation, communications and population flows commonly referred to as "globalization." At the same time, inter-state borders remain central to the global mobility regime, both in terms of the "international management of populations" (Hindess 2000) but also the management of labour flows (Heyman 2004; Sassen 1998). We have witnessed the emergence of a complex series of commercial and state initiatives designed to address the dual need to facilitate the global mobility of labour and goods on the one hand, while identifying and reducing uncertainties and risks associated with human travel and migration on the other. Significantly, the storage and transmission of data, including cross-border flows of personal information, has come to be viewed as essential for addressing both sets of concerns. The generation and sharing of information now underpins security, policing, and the regulation of mobility within states just as it does in the case of international security and trade agreements. This reality is in turn implicated in the fragmentation and displacement of the border vis-à-vis the tracking of persons and things at de-territorialized nodal points of information exchange, and in associated zones of confinement and regulated movement.

The interplay of surveillance and mobility has a long history, growing from historical fears of invasion, disease, and mass migration. However, the sinews of empire and the current network society of globalization depend on the free mobility of at least some portion of the global population. Indeed, as Foucault foresaw, one might say that "the idea of the panopticon is completely archaic," reliant as it is on "an exhaustive surveillance" (2007: 66). For space to open up, for circulation to take place, "we see the emergence of a completely different problem" that is not about strict demarcating but "allowing circulations to take place, controlling them, sifting the good and the bad, ensuring that things are always in movement" (2007: 65). New freedoms or possibility of movement is crucial to the positive message of globalization. But, in addition to the accrual of suspicion towards the "usual suspects" of the poor, the dangerous, the unknown, and the vagabond, there is a new suspicion towards mobility and particularly international mobility itself. Packer argues that "the governance of mobility then needs to be understood in terms of this new problematic, mobility as immanent threat... mobile conduct is not treated as constitutively productive, but rather as potentially destructive" (2006: 382). What is worrisome about this automated governance of mobilities is that "identities become risk assessment algorithms of mobilities. It is not who is a threat, but "what vehicular movement can be used to predict a threat," (392) which leads to the dream or goal of total surveillance and remote control. The border becomes a crucial site of surveillance, where identities, mobilities, and narratives are examined by agents of the state.

The contributors to this issue examine various instances of border securitization, allowing the reader to consider the general developments cited above in terms of their manifestation at the local/national level. To contribute to the transnationalization of surveillance studies, the authors present the cases of France, Australia, and the USCanada border. Ceyhan, Wilson and Weber usefully introduce us to scholars working on these issues from the perspective of national policy analysis, rather than with global surveillance studies. Ceyhan notes that while a preoccupation with tracking and monitoring "risky people" has led to the promotion of a wide range of surveillance 
technologies in the cases of both France and the US, there are also national differences in terms of which persons are viewed as most risky. Unlike the US, the French government is largely concerned with illegal migrants from its former colonies and generally differentiates immigrants and delinquents from the category of terrorist, ranking the former above terrorists as problem categories. Ceyhan also usefully situates the history of biometric technologies for identification and policing in a genealogy that precedes what we have come to know as the "war on terror."

Wilson and Weber also call attention to the ways in which the framing of the idea of nation and citizenship may influence the perception and practices of border security. Policing of the Australian border they argue, has a specific genealogy; driven in part by xenophobic imaginings of a white Australian nation overrun by Asiatic multitudes invading from the North and in part by recent experiences with asylum claimants. Fears originating in Australia's colonial past now inform and intensify public debate about border control. Wilson and Weber combine attention to this national context with consideration of global trends in pre-emptive border clearance and the use of data-mining technologies.

Even as they attenuate at the national or regional scales, objects of fear and technologies of security converge. Ceyhan reminds us that in the post Cold War era the terrorist is the overlapping figure, one which may become superimposed on other categories such as the dual national, the citizen with foreign ancestors, the commuter, the poor, or the antiglobalization protestor. Similarly, technological initiatives originating in one locale - and often for civilian purposes - may quickly be integrated into larger apparatuses of security and risk assessment. The accelerating spread of biometric and other security technologies has been fueled in part by the privatization of security with its accompanying narratives of risk management and promotion of technological fixes for social problems. In the case of the Australian border, Wilson and Weber note that changes to the character of political discourse - including the reframing of mobility as a security problem - echo global trends even as they play to local fears. In the process the new discourses of security and risk squeeze out space for considerations of human rights which do not belong within the paradigm of safety/security.

Technologies of the border not only converge, but also spread throughout governance and across jurisdictions. Many countries of the global North now export their security products as well as their expertise. As Amoore (2006) has observed elsewhere, the techniques of authorization associated with biometric border technologies allow the surveillance of mobility to be practiced by private security firms and homeland security citizens alike. This situation aids in the governing of mobility under the rubric of the war on terror, segregating "legitimate" mobilities such as leisure and business, from "illegitimate" mobilities such as terrorism and illegal immigration. However, while biometrics have arguably become the ubiquitous and mobile border in the war on terror, the mechanisms and data-pathways which allow security systems to function remain opaque to the majority of those under surveillance, frequent flyers and members of the kinetic underclass alike.

In her contribution to this issue, Cote-Boucher argues that the assemblage of disparate mechanisms, institutions, discourses and practices which have come to be conceptualized 
as Canada's "smart border," is best understood as an apparatus or "programme" in the sense formulated by Foucault. Despite the apparent sophistication of this "programme of government of movement," the various strategies it proposes may not all be coherent, and may be superposed, opposed or even abandoned over time. The smart border is a diffuse one physically extending both beyond and inside its geopolitical location, and involving a multiplicity of sites for the surveillance of movement. Nonetheless, in the uncertain processes leading to their implementation "strategies produce effects, some of them unintended, yet always concrete." Significantly, the apparatus renders some objects visible and others invisible as it generates new security language and produces typologies of objects according to the calculus of risk. Cote-Boucher warns that these typologies include highly racialized categories of persons, made meaningful by the intersection of the new security paradigm with older Orientalist discourses. The border's dispersal is necessitated by the tracking of persons and objects, whose mobility is accompanied by profiles, narratives, and data-shadows.

What else besides fear, technological fetishism and the profit motive might lie behind the security and border policing initiatives which have become the hallmark of liberal democracies? As Lyon (2003) has made clear, technological solutions such as those associated with the biometric border are likely to offer little in the way of real security. And yet technologies and policies continue to be imposed upon relatively accommodating publics. deLint offers a fresh perspective on this issue by pointing to the collusion between the security performances of the state and the expectations of the public as audience. He argues convincingly that in the present era of high modernity - a time when states are increasingly unable to affect real control - the currency of production values count. Interruptions of freedom at the border, the airport or other public spaces may not provide actual solutions to real threats, but this is unimportant when such threats remain an "unknown unknown." Hence we may appreciate "mistakes" such as the arrest of celebrities at airports or glitches with no-fly lists not as kinks to be smoothed out of an unfinished security machinery, but rather as performative displays in which "we" must be seen to be as unpredictable and random as the unknown monsters which stalk us. This provocative dramaturgical analysis demonstrates the need to understand both the actions of the watchers and the behaviours of the watched.

The multi-media artistic presentation assembled by Monika Codoury provides an artistic intervention in the lines of sight we usually deploy for thinking about the phenomena discussed in this issue. Focusing on the Frankfurt airport, Codoury draws our attention to the physical spaces, enclosures, and schedules - chosen or imposed - which separate the kinetic elite from the kinetic underclass. While some traverse the globe with relative ease and comfort, for most such mobility is either a non-possibility or a potential source of stress and anxiety. In common with a growing body of artists seeking to make visible that which would otherwise go unnoticed in border security rituals - Rozalinda Borcila, Marcos Ramirez Erre, Ricardo Dominguez - Coudorey’s work contrasts the vulnerability of asylum seekers and refugees held in a concentration facility outside the main airport facility with the waiting areas, consumption opportunities and amenities available to business travelers. 
One area to which all of our contributors call attention concerns the potential consequences of the border and security regimes for real people. As Amoore and DeGoede (2005) have warned, contemporary border security practices have been characterized by a logic whereby risk is managed precisely via its displacement onto the most vulnerable and marginal groups. The production of new border control technologies and practices is targeted at those classified as "selectees," such that backscatter X-ray, for example, becomes an invasion of privacy specifically experienced by the high risk rated people in systems of Automated Targetting and e-Borders. In each of the contributions represented here we can see this sifting or sorting of mobile bodies taking place, and the very real and violent effects that materialize.

These realities draw attention to the continued importance of such social identifiers as class, nationality and ethnicity. Though perhaps distinctively and specifically inscribed for the contemporary moment, nonetheless the visible and visceral practice of racial prejudice at the border is replaced by a less visible and pernicious categorization by algorithm or past travel pattern. In this border regime, a traveler or migrant with family in Pakistan (and past travel patterns to Pakistan), for example, is as likely to be invisibly flagged as risky by an algorithm in US VISIT or e Borders as she is to be prejudicially singled out by the border guard.

The interventions of this issue contribute both to the theoretical discussion of mobility and surveillance and to the comparative analysis of differential and interlocking systems of surveillance. By placing an emphasis on the practices of border policing, we hope to illustrate the importance of this kind of situated meso- and micro-analyses for both border studies and surveillance studies. These pieces demonstrate how close analysis of the practices of surveillance can inform, and be informed by, a host of other political practices. Further research on the actual empirics of border policing is needed to better understand the dynamic tension between freedom of mobility and the provision of security.

\section{References}

Amoore, L. (2006) 'Biometric borders: Governing mobilities in the war on terror,' Political Geography, 25: 336-351.

Amoore, L. and DeGoede, M. (2005) 'Governance, risk and dataveillance in the war on terror,' Crime, Law and Social Change, 43: 149-173.

Foucault, M. (2007) Security, Territory, Population: Lectures at the Collège de France 1977-78, Basingstoke: Macmillan.

Hindess, B. (2000) 'Citizenship in the International Management of Populations,' American Behavioral Scientist, 43(9): 1486-97.

Lyon, D. (2003) 'Airports as Data Filters: Converging Surveillance Systems after September 11,' Information, Communication and Ethics in Society, 1(1): 13-20.

Packer, J. (2006) 'Becoming bombs: mobilizing mobility in the war on terror,' Cultural Studies, 20 (4/5): 378-399. 
Sassen, S. (1998) Globalization and Its Discontents, New York: New Press.

Zureik, E. and Salter, M.B. (2005) 'Who and What Goes Where? Global Policing and Surveillance,' in M.B. Salter and E. Zureik (eds) Global Surveillance: Borders, Security, Identity, Cullumpton: Willan Publishing, UK, 1-10. 